\title{
A Case of Thyroid Crisis With Worsening Jaundice Despite Improvements in Heart Failure
}

\author{
Hiroshi Yamaguchi ${ }^{\mathrm{a}, \mathrm{f}}$, Ayaka Takahashi ${ }^{\mathrm{b}}$, Atsuhisa Shirakami ${ }^{\mathrm{a}}$, Norihito Kageyama ${ }^{\mathrm{c}}$, \\ Ken-ichi Kitazoe $^{d}$, Hiroyuki Fujinaga ${ }^{\mathrm{e}}$
}

\begin{abstract}
We herein present a case of a 33-year-old woman who was referred to our hospital for dyspnea on effort 2 months before her admission. Although diffuse enlargement of the thyroid gland occurred at the age of 23, she did not undergo detailed medical examinations. She was diagnosed with hyperthyroidism due to Graves' disease, and the administration of methimazole was initiated at a dosage of $30 \mathrm{mg} /$ day. She had congestive heart failure, rapid atrial fibrillation, and disseminated intravascular coagulation on admission. Thyroid crisis was diagnosed based on the diagnostic criteria of the Japan Endocrine Society (second edition). Although cardiac function and heart failure symptoms improved, her total bilirubin level continued to increase and peaked at $28.8 \mathrm{mg} / \mathrm{dL}$. Her bilirubin level was reduced by anti-thyroid drugs and eventually normalized in parallel with improvements in thyroid function. Jaundice may have occurred as a secondary consequence of cholestasis due to hyperthyroidism because other causes such as drug-induced or autoimmune liver dysfunction were ruled out. We herein report a rare case of thyroid crisis with worsening jaundice despite improvements in heart failure. This case demonstrated that obtaining a detailed medical history and a careful examination of the clinical course were useful for reaching the differential diagnosis of severe jaundice and achieving steady improvements in this serious medical condition.
\end{abstract}

Keywords: Thyroid crisis; Graves' disease; Jaundice; Atrial fibrilla-

Manuscript accepted for publication April 07, 2016

aDepartment of Diabetology and Metabolic Medicine, Tokushima Prefectural Central Hospital, Kuramoto, 1-10-3, Tokushima 770-8539, Japan

bDepartment of Therapeutic Radiology, Institute of Biomedical Sciences, Tokushima University Graduate School, 3-18-15 Kuramoto-cho, Tokushima, Tokushima 770-8503, Japan

'Department of Cardiology, Tokushima Prefectural Miyoshi Hospital, 815-2 Shima, Ikeda-Cho, Miyoshi-Shi, Tokushima 778-8503, Japan

dDepartment of Gastroenterology, Tokushima Prefectural Central Hospital, Kuramoto, 1-10-3, Tokushima 770-8539, Japan

eDepartment of Cardiology, Tokushima Prefectural Central Hospital, Kuramoto, 1-10-3, Tokushima 770-8539, Japan

${ }^{\mathrm{f} C}$ Corresponding Author: Hiroshi Yamaguchi, Department of Diabetology and Metabolic Medicine, Tokushima Prefectural Central Hospital, Kuramoto, 1-10-3, Tokushima 770-8539, Japan. Email: futuyaso007@yahoo.co.jp

doi: http://dx.doi.org/10.14740/jem345w tion; Heart failure; Cholestatic hepatic injury

\section{Introduction}

Thyroid storm is the sudden, life-threatening exacerbation of thyrotoxicosis that is associated with multiorgan dysfunction and a high risk of mortality if untreated. Although liver injury caused by thyrotoxicosis due to Graves' disease is relatively common, it is less likely to be as serious as clinically obvious liver disease. Liver dysfunction has been divided into the hepatic type (transaminase elevations) or cholestatic type [1, 2]. Jaundice is occasionally a symptom of heart failure due to passive congestion in the liver or acute ischemic hepatitis [3]. However, it is less likely to show a very high serum total bilirubin level that reaches $28.8 \mathrm{mg} / \mathrm{dL}$, as was observed in the present case. We herein report a case of severe cholestatic jaundice associated with thyroid crisis in the absence of a history of liver disease, which may not have been due to other causes such as heart failure or drug-induced or autoimmune liver dysfunction. We also discuss other relevant reports available in the literature.

\section{Case Report}

We herein present a case of a 33-year-old woman who was referred to our hospital for dyspnea on effort 2 months before her admission. Although diffuse enlargement of the thyroid gland occurred at the age of 23 , she did not undergo more detailed examinations or receive appropriate treatments. Her conscious level was slightly decreased and she had intermittent finger tremors. A physical examination revealed severe jaundice in the skin of the whole body and bulbar conjunctiva, bilateral mild exophthalmos, thyroid gland enlargement with vascular bruit, tachycardia, and pitting edema in both legs. She had no risk factors for liver disease, and also had no history of blood transfusions, alcohol use, intravenous drug use, or viral hepatitis. On admission, her vital signs were as follows: height, 149 $\mathrm{cm}$; weight, $30.8 \mathrm{~kg}$; body temperature, $37.1^{\circ} \mathrm{C}$; blood pressure, $70 / 30 \mathrm{~mm} \mathrm{Hg}$; heart rate, 140 - 150 beats/min with atrial fibrillation; respiratory rate, 20 breaths $/ \mathrm{min} ; \mathrm{SpO}_{2} 99 \%$ (on room air). Chest X-ray revealed massive cardiomegaly (car- 


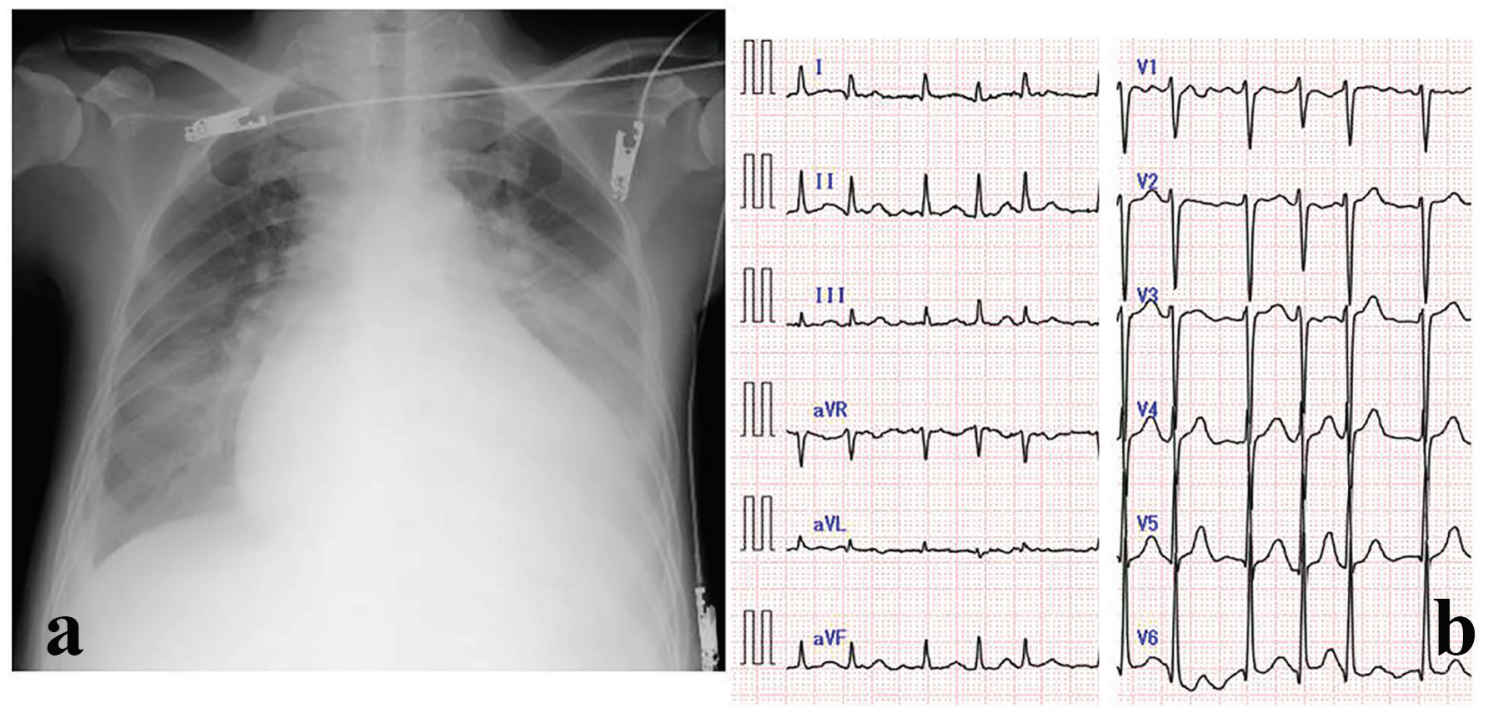

Figure 1. (a) Chest X-ray and (b) electrocardiogram on admission.

diothoracic ratio: $70.3 \%$ ) and a congestive image on both sides of the lung field (Fig. 1a). Electrocardiography showed rapid atrial fibrillation at a heart rate of 140 beats/min (Fig. 1b). She was diagnosed with congestive heart failure and rapid atrial fibrillation caused by hyperthyroidism. The administration of vasodilators, catecholamines, and diuretics was initiated immediately, and non-invasive positive pressure ventilation was attached for respiratory failure due to decompensated heart failure. Her serum BNP level was subsequently found to be elevated $(836 \mathrm{pg} / \mathrm{mL}(0.0$ - 18.4)). A cervical ultrasound revealed an enlarged thyroid gland and heterogeneous parenchyma without nodule formation. Color Doppler imaging of the thyroid showed markedly increased blood flow inside the thyroid gland. Echocardiography showed diffuse reduced left ventricle wall motion (left ventricular ejection fraction (LVEF); 20$25 \%)$ ) and dilatation of the left ventricular end-diastolic diameter $(61 \mathrm{~mm})$. The results of the laboratory examination on admission are shown in Table 1.

She was diagnosed with hyperthyroidism due to Graves' disease because thyroid function tests revealed a reduced thyroid-stimulating hormone level (TSH) of $0.003 \mu \mathrm{IU} / \mathrm{mL}$ (normal range: 0.35 - 4.94), elevated free thyroxine level (free T4) of $7.0 \mathrm{ng} / \mathrm{dL}(0.7-1.5)$, and free triiodothyronine level (free T3) of $17.2 \mathrm{pg} / \mathrm{mL}(1.7-3.7)$, and thyroid autoantibodies were positive (thyroid-stimulating antibody (TSAb) $330 \%(0$ - 179) and TSH receptor antibody (TRAb) $7.1 \mathrm{IU} / \mathrm{L}(0.0-0.9))$. The administration of the thyrostatic drug, methimazole (MMI) was initiated at a dose of $30 \mathrm{mg} /$ day. The state of thyroid crisis due to untreated Graves' disease was diagnosed based on the diagnostic criteria of the Japan Endocrine Society (second edition) [4] because she had the following diagnostic items: tachycardia, heart failure symptoms, and gastrointestinal symptoms including diarrhea and jaundice. Since her Burch-Wartofsky score for thyroid storm was 95 , the diagnostic criteria were also fulfilled [5]. Her platelet count decreased to $106,000 / \mu \mathrm{L}$, her prothrombin time was less than $5.0 \%$, fibrinogen decreased to $107 \mathrm{mg} / \mathrm{dL}$, and her FDP-D level was slightly increased to
$12.3 \mu \mathrm{g} / \mathrm{mL}$, which was consistent with disseminated intravascular coagulation (DIC). Heparin, antithrombin III, and gabexate mesilate were started for DIC at the appropriate time during her clinical course. Although her free T4 level remained high (free T4: $6.1 \mathrm{ng} / \mathrm{dL}$ ), LVEF improved from approximately $20 \%$ to $56 \%$ on the 17 th day after her admission. Total bilirubin (T-bil), in which direct bilirubin was dominant, continued to increase, reaching $28.8 \mathrm{mg} / \mathrm{dL}$ on the 23rd day (Fig. 2).

On the 26th day, she developed aspiration pneumonia and fell into a deep coma. This symptom of the central nervous system was attributed to the exacerbation of thyroid crisis because infection was a precipitating factor. She was transferred to the medical intensive care unit, and bilirubin adsorption therapy (Medisorba ${ }^{\circledR} \mathrm{BL}$, Kawasumi Laboratories, Inc.), which was only covered by national health insurance system of Japan for the treatment of fulminant hepatitis, was performed for severe jaundice and deep coma on the 29th day. Although her serum T-bil level temporarily decreased from 26 to $10.6 \mathrm{mg}$ / $\mathrm{dL}$ after adsorption therapy, it increased again to $17.9 \mathrm{mg} / \mathrm{dL}$ on the next day. Her serum bilirubin level gradually decreased with improvements in thyroid hormone levels. Serum thyroid hormone levels normalized on the 48th day, and her serum Tbil level decreased to $1.5 \mathrm{mg} / \mathrm{dL}$ on the 77 th day. Her mental status gradually improved in proportion to her recovery from thyroid storm. She was discharged on the 80th day with an improved condition and subsequently treated as an outpatient at our hospital. Her serum bilirubin level had returned to within normal ranges (T-bil $0.8 \mathrm{mg} / \mathrm{dL}(0.1-1.0)$ ) by the follow-up 45 days later, and atrial fibrillation had been restored to a sinus rhythm by the follow-up 73 days later. A year and a half later, she underwent subtotal thyroidectomy for the reactivation of hyperthyroidism.

\section{Discussion}

Hepatic dysfunction is commonly observed in patients with 
Table 1. Laboratory Findings on Admission

\begin{tabular}{|c|c|}
\hline \multicolumn{2}{|l|}{ Urinalysis } \\
\hline Protein & $2+$ \\
\hline Glucose & - \\
\hline Ketone bodies & - \\
\hline Bilirubin & $1+$ \\
\hline \multicolumn{2}{|l|}{ Blood cell count } \\
\hline WBC & $4,500 / \mu \mathrm{L}$ \\
\hline $\mathrm{RBC}$ & $352 \times 10^{4} / \mu \mathrm{L}$ \\
\hline $\mathrm{Hb}$ & $9.7 \mathrm{~g} / \mathrm{dL}$ \\
\hline Plt & $10.6 \times 10^{4} / \mu \mathrm{L}$ \\
\hline \multicolumn{2}{|l|}{ Serological test } \\
\hline CRP & $0.41 \mathrm{mg} / \mathrm{dL}$ \\
\hline HBs Ag & - \\
\hline $\mathrm{HCV} \mathrm{Ab}$ & - \\
\hline \multicolumn{2}{|l|}{ Blood chemistry } \\
\hline T-bil & $4.9 \mathrm{mg} / \mathrm{dL}$ \\
\hline AST & $32 \mathrm{U} / \mathrm{L}$ \\
\hline ALT & $23 \mathrm{U} / \mathrm{L}$ \\
\hline LDH & $245 \mathrm{U} / \mathrm{L}$ \\
\hline ALP & $779 \mathrm{U} / \mathrm{L}$ \\
\hline$\gamma$-GTP & $54 \mathrm{U} / \mathrm{L}$ \\
\hline CK & $95 \mathrm{U} / \mathrm{L}$ \\
\hline T-cho & $78 \mathrm{mg} / \mathrm{dL}$ \\
\hline TG & $37 \mathrm{mg} / \mathrm{dL}$ \\
\hline TP & $7.5 \mathrm{~g} / \mathrm{dL}$ \\
\hline $\mathrm{Alb}$ & $2.3 \mathrm{~g} / \mathrm{dL}$ \\
\hline BUN & $13.7 \mathrm{mg} / \mathrm{dL}$ \\
\hline $\mathrm{Cr}$ & $0.35 \mathrm{mg} / \mathrm{dL}$ \\
\hline $\mathrm{Na}$ & $138 \mathrm{mEq} / \mathrm{L}$ \\
\hline $\mathrm{K}$ & $4.2 \mathrm{mEq} / \mathrm{L}$ \\
\hline $\mathrm{Cl}$ & $105 \mathrm{mEq} / \mathrm{L}$ \\
\hline Glucose & $104 \mathrm{mg} / \mathrm{dL}$ \\
\hline $\mathrm{HbAlc}$ & $5.2 \%$ \\
\hline \multicolumn{2}{|c|}{ Endocrine examination } \\
\hline Free T3 & $17.2 \mathrm{pg} / \mathrm{mL}$ \\
\hline Free $\mathrm{T} 4$ & $7.0 \mathrm{ng} / \mathrm{dL}$ \\
\hline TSH & $0.003 \mu \mathrm{IU} / \mathrm{mL}$ \\
\hline TSAb & $330 \%$ \\
\hline TRAb & $7.1 \mathrm{IU} / \mathrm{L}$ \\
\hline TPOAb & $180 \mathrm{IU} / \mathrm{mL}$ \\
\hline $\mathrm{TgAb}$ & $104 \mathrm{IU} / \mathrm{mL}$ \\
\hline ACTH & $254 \mathrm{pg} / \mathrm{mL}$ \\
\hline Cortisol & $17.7 \mu \mathrm{g} / \mathrm{dL}$ \\
\hline BNP & $836 \mathrm{pg} / \mathrm{mL}$ \\
\hline \multicolumn{2}{|l|}{ Hemostatic test } \\
\hline PT & $>120 \mathrm{~s}$ \\
\hline PT\% & $<5.0 \%$ \\
\hline Fib & $107 \mathrm{mg} / \mathrm{dL}$ \\
\hline ATIII & $22.3 \%$ \\
\hline FDP & $12.3 \mu \mathrm{g} / \mathrm{mL}$ \\
\hline D-dimer & $4.8 \mu \mathrm{g} / \mathrm{mL}$ \\
\hline
\end{tabular}

TgAb: anti-thyroglobulin antibody; TPOAb: anti-thyroid peroxidase antibody; TRAb: TSH receptor antibody; TSAb: thyroid-stimulating antibody; Fib: fibrinogen. thyroid disease because thyroid hormones are glucuronidated and sulfated within the liver and subsequently excreted into bile, and also maintain the metabolism of bilirubin by regulating glucuronyl transferase and ligandin, a hepatic transport protein [6]. A large number of case reports and series have reported the prevalence of liver test abnormalities, ranging between $15 \%$ and $76 \%$ of patients with hyperthyroidism $[6,7]$. Severe liver dysfunction or severe jaundice is an uncommon state in patients with Graves' disease; however, thyrotoxicosis and intrinsic liver disease need to be excluded when it does occur [8].

Cholestatic hepatic injury in patients with hyperthyroidism or thyroid crisis due to Graves' disease has been associated with other autoimmune diseases such as primary biliary cirrhosis or autoimmune hepatitis, and has been reported in up to $10 \%$ of cases $[9,10]$. Jaundice may also occur due to hepatic congestion from thyrotoxic heart failure, the side effects of anti-thyroid drugs, and hepatic necrosis from systemic embolization caused by atrial fibrillation [6]. In the present case, serological tests for hepatitis B, C, antinuclear antibodies, and serum anti-mitochondrial antibodies were negative. Since transaminase levels continued to be mildly elevated in spite of severe jaundice, the pattern of liver injury in this case was regarded as the cholestatic type.

MMI, which was used in the present case, has also been reported to cause liver function abnormalities, but at a lower frequency than that of propylthiouracil (PTU). Jaundice due to MMI appears to be due to a hypersensitivity reaction in patients receiving normal doses of the drug, and is generally associated with cholestatic liver dysfunction [11]. This side effect typically results in the discontinuation of this drug therapy. Based on her clinical course, in which the administration of MMI was continued because jaundice had improved, MMI was considered to be irrelevant to liver injury. Although liver biopsy is a useful method for ruling out the involvement of infectious or autoimmune etiologies, we did not perform this procedure because it is too invasive for critically ill patients with DIC, as in the present case.

On the other hand, although severe jaundice is an uncommon presentation of cardiac diseases, two major causes may be chronic congestion due to heart failure and ischemic hepatitis from acute circulatory impairments [3]. Severe liver test abnormalities such as severe jaundice and a prolonged prothrombin time may occur in patients with hyperthyroidism alone or with hyperthyroidism and congestive heart failure. Therefore, the diagnosis of concomitant or unrelated liver disease is difficult until hyperthyroidism has been controlled. Although serum bilirubin levels in the present case steadily increased despite improvements in heart failure symptoms and cardiac function, serum bilirubin levels gradually decreased with reductions in thyroid hormone levels, which is consistent with previously reported cases [12-15]. Collectively, our results implicated thyroid crisis due to Graves' disease as the cause of severe jaundice in this case.

The liver is the primary organ for thyroid hormone metabolism, and mild liver dysfunction is commonly associated with hyperthyroidism. However, there has been no evidence to suggest that thyroid hormones have a direct toxic effect on the liver [14], and hyperthyroidism manifesting as clinical icterus is extremely rare, such as in the present case. The following 


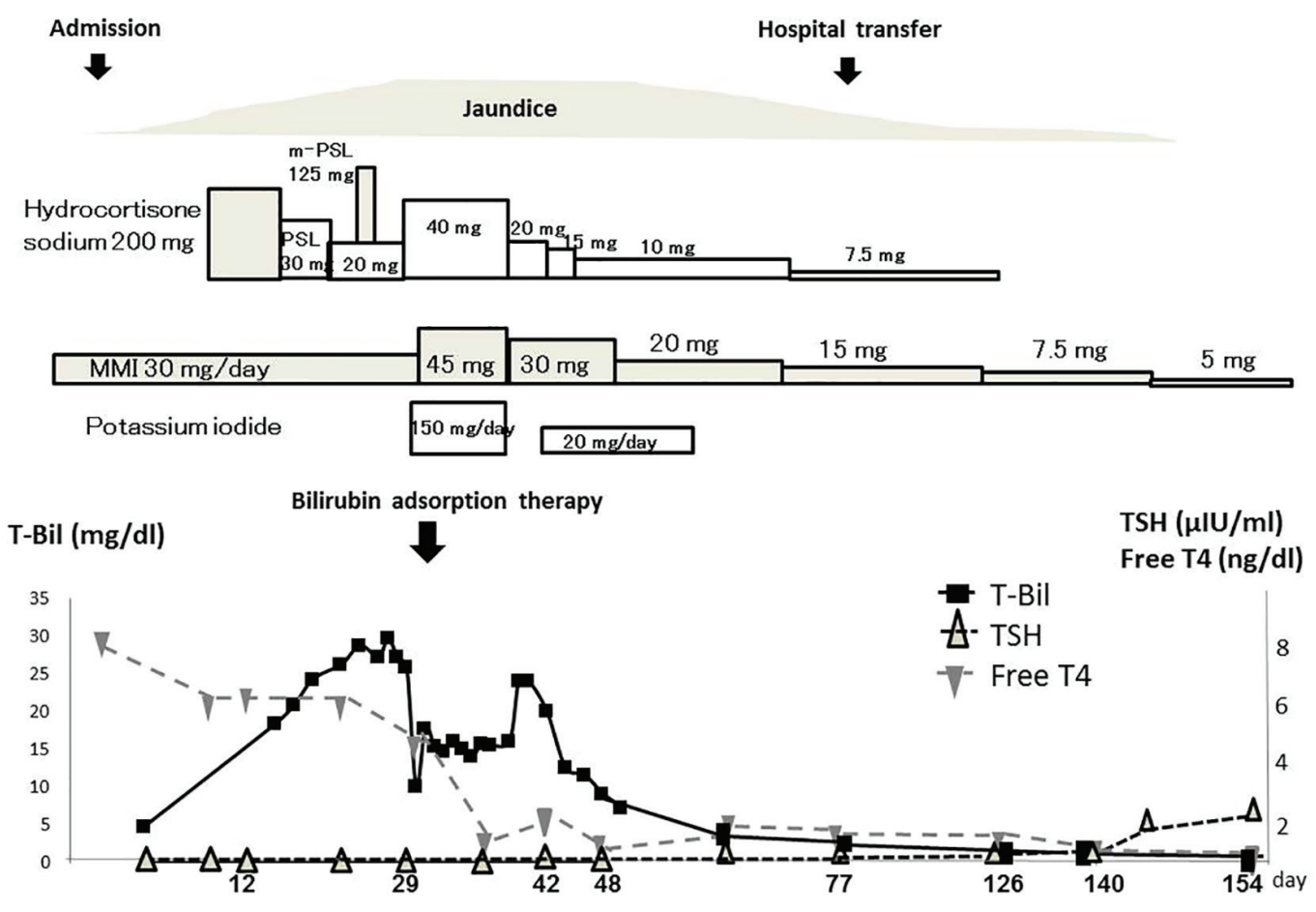

Figure 2. Clinical course of the patient.

hypothesis has been proposed for the cause of cholestasis in thyrotoxicosis; an increase in hepatic oxygen consumption without elevations in hepatic blood flow in patients with a hypermetabolic state in hyperthyroidism reduces oxygen tension in the centrilobular zones and interferes with bile transport, resulting in cholestasis and increases in the rate of bile flow to the point of saturation $[11,16]$.

\section{Conclusion}

We herein report a very rare case of thyroid crisis with worsening jaundice despite improvements in heart failure. The results obtained and clinical course suggest that hyperbilirubinemia during severe thyroid crisis occurred as a secondary consequence of hyperthyroidism. A detailed examination of the clinical course was useful for reaching the differential diagnosis of severe jaundice. This case demonstrates that the rapid recognition of severe jaundice due to hyperthyroidism after a thorough evaluation for other causes of liver disease leads to steady improvements in this serious medical condition.

\section{Conflicts of Interest}

The authors declare no relevant of interest.

\section{References}

1. Malik R, Hodgson H. The relationship between the thy- roid gland and the liver. QJM. 2002;95(9):559-569.

2. Hegazi MO, Ahmed S. Atypical clinical manifestations of graves' disease: an analysis in depth. J Thyroid Res. 2012;2012:768019.

3. van Lingen R, Warshow U, Dalton HR, Hussaini SH. Jaundice as a presentation of heart failure. J R Soc Med. 2005;98(8):357-359.

4. www.japanthyroid.jp/doctor/img/crisis2.pdf.

5. Burch HB, Wartofsky L. Life-threatening thyrotoxicosis. Thyroid storm. Endocrinol Metab Clin North Am. 1993;22(2):263-277.

6. Khemichian S, Fong TL. Hepatic dysfunction in hyperthyroidism. Gastroenterol Hepatol (N Y). 2011;7(5):337339.

7. Fong TL, McHutchison JG, Reynolds TB. Hyperthyroidism and hepatic dysfunction. A case series analysis. J Clin Gastroenterol. 1992;14(3):240-244.

8. Soysal D, Tatar E, Solmaz S, Kabayegit O, Tunakan M, Unsal B, Cevik C. A case of severe cholestatic jaundice associated with Graves' disease. Turk J Gastroenterol. 2008;19(1):77-79.

9. Kibirige D, Kiggundu DS, Sanya R, Mutebi E. Cholestatic hepatic injury due to a thyroid storm: a case report from a resource limited setting. Thyroid Res. 2012;5(1):6.

10. Boelaert K, Newby PR, Simmonds MJ, Holder RL, CarrSmith JD, Heward JM, Manji N, et al. Prevalence and relative risk of other autoimmune diseases in subjects with autoimmune thyroid disease. Am J Med. 2010;123(2):183 e181-189.

11. Bal C, Chawla M. Hyperthyroidism and jaundice. Indian J Nucl Med. 2010;25(4):131-134. 
12. Harada Y, Akiyama H, Yoshimoto T, Urao Y, Ryuzaki M, Handa M. Thyroid storm with multiple organ failure, disseminated intravascular coagulation, and stroke with a normal serum FT3 level. Intern Med. 2012;51(17):23792383.

13. Ichikawa H, Ebinuma H, Tada S, Ojiro K, Yamagishi Y, Tsukada N, Hongou E, et al. A case of severe cholestatic jaundice with hyperthyroidism successfully treated with methimazole. Clin J Gastroenterol. 2009;2(4):315-319.
14. Usta Y, Massaad J, Parekh S, Knecht L. Severe cholestatic jaundice secondary to hyperthyroidism. IJCRI. 2013;4:212-215.

15. Hull K, Horenstein R, Naglieri R, Munir K, Ghany M, Celi FS. Two cases of thyroid storm-associated cholestatic jaundice. Endocr Pract. 2007;13(5):476-480.

16. Yao JD, Gross JB, Jr., Ludwig J, Purnell DC. Cholestatic jaundice in hyperthyroidism. Am J Med. 1989;86(5):619620. 